\title{
Farelo de mandioca na ensilagem de capim-elefante: fracionamento de carboidratos e proteínas e características fermentativas
}

\author{
Cassava meal in the elephant grass silage: carbohydrate and protein fractioning and \\ fermentation characteristics of silage elephant grass
}

\author{
OLIVEIRA, Aline Cardoso ${ }^{1 *}$; GARCIA, Rasmo ${ }^{2}$; PIRES, Aureliano José Vieira ${ }^{3}$; \\ OLIVEIRA, Hellenn Cardoso ${ }^{2}$; ALMEIDA, Vitor Visintin Silva de ${ }^{4}$; VELOSO, \\ Cristina Mattos ${ }^{2}$; ROCHA NETO, Aires Lima ${ }^{4}$; OLIVEIRA, Ueslei Leonardo Cardoso ${ }^{5}$
}

\footnotetext{
${ }^{1}$ Universidade Estadual do Sudoeste da Bahia, Programa de Pós-Graduação em Zootecnia, Itapetinga, Bahia, Brasil.

${ }^{2}$ Universidade Federal de Viçosa, Centro de Ciências Agrárias, Departamento de Zootecnia, Viçosa, Minas Gerais, Brasil.

${ }^{3}$ Universidade Estadual do Sudoeste da Bahia, Programa de Pós-Graduação em Zootecnia, Itapetinga, Bahia, Brasil.

${ }^{4}$ Instituto Federal de Educação, Ciência e Tecnologia Baiano, Santa Inês, Bahia, Brasil.

${ }^{5}$ Universidade Estadual de Santa Cruz, Programa de Pós-Graduação em Produção Vegetal, Itabuna, Bahia, Brasil.

*Endereço para correspondência: oliveyra_aline@yahoo.com.br
}

\section{RESUMO}

Objetivou-se determinar as frações que compõem os carboidratos e as proteínas, bem como as características fermentativas da silagem de capim-elefante, sem e com emurchecimento, e acrescida de farelo de mandioca. Foi adotado o esquema fatorial 4 × 2 , com quatro repetições no delineamento inteiramente casualizado. Os fatores avaliados foram níveis de farelo de mandioca $(0 ; 7,5 ; 15$ e $22,5 \% \quad M N)$ e emurchecimento (sem e com). Foram usados silos de PVC, com $50 \mathrm{~cm}$ de altura e $10 \mathrm{~cm}$ de diâmetro para a produção das silagens. As frações de $\mathrm{CHO}(\mathrm{A}+\mathrm{B} 1$ e $\mathrm{B} 2)$ e as frações nitrogenadas B3 e $\mathrm{C}$ foram influenciadas pela associação do emurchecimento aos níveis de farelo de mandioca, o que não ocorreu com as frações nitrogenadas (A e B1+B2) das silagens. $A$ adição de farelo de mandioca reduziu linearmente a fração $\mathrm{C}$ dos carboidratos. No que concerne às características fermentativas das silagens, o $\mathrm{pH}$ apresentou comportamento quadrático. $\mathrm{O}$ nitrogênio amoniacal apresentou comportamento quadrático e linear decrescente para as silagens sem e com emurchecimento, respectivamente. A utilização do farelo de mandioca reduz a fração B2 e a porção de carboidratos indisponíveis. As principais frações proteicas das silagens estudadas são as frações $\mathrm{A}$ e B1+B2. O emurchecimento e a adição de farelo de mandioca melhoram o valor nutritivo e as características fermentativas das silagens estudadas.

Palavras-chaves: fermentação, gramínea, nitrogênio, Pennissetum purpureum, subproduto.

\section{SUMMARY}

The objective of this work was to determine the fractions that compose the carbohydrates (CHO) and proteins and fermentative characteristics of elephant grass silage without or with wilting and added of cassava meal. The $4 \times 2$ factorial scheme was adopted, with four repetitions, in a completely randomized design. The factors evaluated were wilting (without and with) and cassava meal levels $(0 ; 7.5 ; 15$ and $22.5 \% \mathrm{DN})$. PVC silos with $50 \mathrm{~cm}$ height and $10 \mathrm{~cm}$ diameter were used for silages production. $\mathrm{A}+\mathrm{B} 1$ and $\mathrm{B} 2$ $\mathrm{CHO}$ fractions and $\mathrm{B} 3$ and $\mathrm{C}$ nitrogen fractions of silages were influenced by association of wilting with cassava meal levels, the wilting and the cassava meal inclusion had no effect on A and $\mathrm{B} 1+\mathrm{B} 2$ nitrogen fractions. The cassava meal addiction linearly reduced the $\mathrm{CHO} \mathrm{C}$ fraction. 
Relative to variables inherent to silages' fermentative characteristics, $\mathrm{pH}$ presented quadratic behavior. Ammonia nitrogen, presented quadratic and decreasing linear behavior for silages without and with wilting, respectively. The use of cassava meal reduces the B2 and unavailable carbohydrates fraction. The main protein fractions of the silages studied are $\mathrm{A}$ and $\mathrm{B} 1+\mathrm{B} 2$ fractions. Wilting and the addition of cassava meal improved the nutritive value and fermentation characteristics of the silages studied.

Keywords: by-product, fermentation, grass, nitrogen, Pennisetum purpureum.

\section{INTRODUÇÃO}

A utilização de silagens de gramíneas forrageiras tropicais tornou-se prática cada vez mais comum na alimentação de ruminantes. Dentre as mais utilizadas, o capim-elefante destaca-se por apresentar grande quantidade de matéria seca produzida por área, quando comparado com as demais espécies. Além disso, trata-se de uma planta perene e com valor nutritivo, o que evita gastos anuais de implantação da cultura (REZENDE et al., 2002).

Embora o capim-elefante apresente boas características de produção, fatores limitantes, como alto teor de umidade e baixas concentrações de carboidratos solúveis podem gerar condições de obtenção de silagens de baixa qualidade. Assim, faz-se necessária a utilização de técnicas que possam elevar o teor de MS da forragem para níveis satisfatórios do ponto de vista da fermentação, no interior do silo.

Dentre as técnicas possíveis, o emurchecimento ou a inclusão de aditivos absorventes e nutritivos, como o farelo de mandioca, pode contribuir para melhoria do valor nutritivo. Ademais, pode contribuir para o aperfeiçoamento das características fermentativas das silagens que devem apresentar $\mathrm{pH}$ de 3,8 a 4,2 e $\mathrm{N}-\mathrm{NH}_{3}$, com valor máximo de $10 \%$, número indicial de fermentação adequada.

Nesse sentido, diversos trabalhos têm sido realizados em busca de alternativas para aumentar o aporte de carboidratos solúveis no momento da ensilagem do capim-elefante (CARVALHO et al., 2007abc; ANDRADE et al., 2010). De acordo com o CNCPS, os alimentos são subdivididos em decorrência de características químicas, físicas, de degradação ruminal e digestibilidade pós-rúmen, sobretudo, para minimizar as perdas de nutrientes. Como consequência, é possível maximizar a eficiência de crescimento microbiano, através da sincronização da degradação de carboidratos e proteínas, para provocar o máximo desempenho teórico dos micro-organismos, reduzir as perdas no rúmen e estimar o escape de nutrientes (MELLO \& NORNBERG, 2004).

Dessa forma, o conhecimento mais aprofundado das frações dos alimentos permite propor alternativas, que reflitam diretamente na melhoria dos sistemas produtivos e promovam um ajuste fino na nutrição animal pela possibilidade de prever o desempenho dos animais (GESUALDI JUNIOR et al., 2005). Objetivou-se determinar as frações que compõem os carboidratos $\mathrm{e}$ as proteínas, bem como as características fermentativas de silagens de capimelefante, com e sem emurchecimento, acrescidas de farelo de mandioca.

\section{MATERIAL E MÉTODOS}

O experimento foi conduzido no Laboratório de Forragicultura e Pastagens, da Universidade Estadual do Sudoeste da Bahia - UESB, Campus de Itapetinga, BA, região Sudoeste, 
localizada a $15^{\circ} 18^{\prime} 14^{\prime \prime}$ de latitude sul e $40^{\circ} 12^{\prime} 10^{\prime \prime}$ de longitude oeste e altitude de $268 \mathrm{~m}$, em janeiro de 2007. As condições climáticas da região foram de $82 \%$ de umidade, precipitação média de $892 \mathrm{~mm}$ e temperatura média de $27^{\circ} \mathrm{C}$.

Foi utilizado o capim-elefante (Pennisetum purpureum, Schum. cv. Napier), cortado aos 60 dias de desenvolvimento e proveniente de uma capineira estabelecida em um solo classificado do tipo Chernossolo argilúvio, ótico, típico, estruturado hipereutrófico, com textura argilosa, fase floresta subcaducifólia e relevo ondulado (EMBRAPA, 2006). Adotou-se o delineamento inteiramente casualizado, com a utilização de um esquema fatorial $4 \times 2$, quatro níveis de farelo de mandioca $(0 ; 7,5 ; 15$ e $22,5 \%$ da $\mathrm{MN})$ ou $(0 ; 20 ; 30$ e $40 \%$ da $\mathrm{MS})$ adicionados ao capim-elefante, com e sem emurchecimento, com quatro repetições.

O material foi picado em ensiladeira regulada para cortar a forragem em pedaços de aproximadamente $2 \mathrm{~cm}$. No processo de emurchecimento, o capim foi colhido e espalhado no campo. Após oito horas de exposição ao sol, foi picado e lhe foi adicionado o farelo de mandioca, por fim, foi ensilado. $\mathrm{O}$ farelo de mandioca aqui utilizado é um subproduto proveniente da lavagem da mandioca triturada para posterior produção da fécula.

$\mathrm{Na}$ incorporação do farelo de mandioca sem emurchecimento, o mesmo foi imediatamente adicionado, logo após o corte do capim e o fracionamento das partículas na ensiladeira, cuja proporção foi adicionada com base na massa verde da gramínea. A composição químicobromatológica do capim-elefante sem emurchecimento, emurchecido e do farelo de mandioca (FM) pode ser observada na Tabela 1.
O material foi armazenado durante 60 dias, em silos de PVC, com $50 \mathrm{~cm}$ de altura e $10 \mathrm{~cm}$ de diâmetro, providos de válvula de Bunsen, para saída de gases, oriundos da fermentação. A compactação foi realizada com soquetes de cimento, com diâmetro de $8 \mathrm{~cm}$ e $15 \mathrm{~cm}$ de altura, a partir da qual se obteve massa específica de $600 \mathrm{~kg}$ de matéria verde $/ \mathrm{m}^{3}$.

Após o período de 60 dias, os silos foram abertos e a coleta de amostras foi feita, as quais foram congeladas para posteriores análises. Estas foram devidamente acondicionadas e transportadas para o Departamento de Zootecnia da Universidade Federal de Viçosa, onde, nos Laboratórios de Forragicultura e de Nutrição Animal, foram processadas e analisadas.

Parte da silagem in natura (50 g) foi triturada com $200 \mathrm{~mL}$ de água, em liquidificador industrial, e filtrada em gaze para extração do meio aquoso, que foi utilizado imediatamente para análise de nitrogênio amoniacal $\left(\mathrm{N}-\mathrm{NH}_{3}\right)$ e $\mathrm{pH}$. $\mathrm{O}$ teor de $\mathrm{N}-\mathrm{NH}_{3}$, como porcentagem do $\mathrm{N}$-Total, foi dosado logo em seguida, com uso de óxido de magnésio e cloreto de cálcio, segundo Cunniff (1995).

Parte das amostras foi descongelada à temperatura ambiente, acondicionada em saco de papel e levada à estufa de présecagem, por 72 horas, à temperatura de $65^{\circ} \mathrm{C}$. Em seguida, foi triturada em moinho de facas tipo Wiley, em peneira com malha de $1 \mathrm{~mm}$. Essas amostras foram utilizadas para se determinar a composição químico- bromatológicas das silagens. Os teores de proteína bruta, NIDN e NIDA foram determinados conforme Silva \& Queiroz (2002).

A fração B3 da proteína foi obtida pela diferença entre o NIDN e o NIDA, ao passo que a proteína verdadeira solúvel em detergente neutro (frações B1+B2), pela diferença entre o $\mathrm{N}$ insolúvel em ácido tricloroacético (TCA), determinado 
Rev. Bras. Saúde Prod. Anim., Salvador, v.13, n.4, p.1020-1031 out./dez., 2012 http://www.rbspa.ufba.br ISSN 15199940

conforme Pereira \& Rossi (1994), e o NIDN.

A porcentagem de carboidratos totais $(\mathrm{CHO})$ foi obtida pela equação: $\mathrm{CHO}=$ $100-(\% \mathrm{~PB}+\% \mathrm{EE}+\%$ cinzas $)-$ (SNIFFEN et al., 1992). Os carboidratos fibrosos (CF) foram obtidos a partir da FDN corrigida para seu conteúdo de cinzas e proteínas (FDNcp); os carboidratos não fibrosos (CNF), que correspondem às frações $\mathrm{A}+\mathrm{B} 1$, pela diferença entre os $\mathrm{CHO}$ e a FDNcp (HALL, 2003); e a fração C, pela FDN indigestível após 144 horas de incubação in situ (CABRAL et al., 2004). A fração B2, ou seja, a fração disponível da fibra, foi obtida pela diferença entre a FDNcp e a fração C.

Tabela 1. Composição química, $\mathrm{pH}$ e digestibilidade in vitro da matéria seca (DIVMS) do capim-elefante e do farelo de mandioca

\begin{tabular}{lccc}
\hline \multirow{2}{*}{ Item } & \multicolumn{2}{c}{ Capim-elefante } & \multirow{2}{*}{ Farelo de mandioca } \\
\cline { 2 - 4 } & Não emurchecido & Emurchecido & 85,1 \\
MS $^{1}$ & 19,5 & 30,0 & 98,6 \\
MO $^{2,13}$ & 91,0 & 91,6 & 2,8 \\
PB $^{3,13}$ & 5,4 & 4,4 & 0,46 \\
$\mathrm{EE}^{4,13}$ & 1,3 & 1,8 & 16,3 \\
$\mathrm{FDN}^{5,13}$ & 71,9 & 69,5 & 12,5 \\
$\mathrm{FDNCP}^{6,13}$ & 66,8 & 65,8 & 8,6 \\
$\mathrm{FDA}^{7,13}$ & 48,2 & 50,0 & 1,4 \\
Cinzas $^{13}$ & 9,0 & 8,4 & 0,86 \\
Lignina $^{13}$ & 6,4 & 6,8 & 6,7 \\
Celulose $^{13}$ & 35,5 & 38,5 & 7,6 \\
$\mathrm{Hemicelulose}^{13}$ & 23,7 & 19,4 & 0,12 \\
NIDN $^{8,13}$ & 0,21 & 0,24 & 0,10 \\
NIDA $^{9,13}$ & 0,16 & 0,17 & 26,8 \\
NIDN $^{8,14}$ & 24,3 & 34,1 & 22,3 \\
NIDA $^{9,14}$ & 18,5 & 24,1 & 95,3 \\
$\mathrm{CHO}^{10}$ & 84,3 & 85,4 & 82,8 \\
CNF $^{11}$ & 17,5 & 19,6 & - \\
pH $^{\text {DIVMS }}$ & 5,5 & 5,31 & 99,0 \\
\hline
\end{tabular}

${ }^{1}$ Teor de matéria seca; ${ }^{2}$ Matéria orgânica; ${ }^{3}$ Proteína bruta; ${ }^{4}$ Extrato etéreo; ${ }^{5}$ Fibra em detergente neutro; ${ }^{6}$ Fibra em detergente neutro corrigido para cinzas e proteína; ${ }^{7}$ Fibra em detergente ácido; ${ }^{8}$ Nitrogênio insolúvel em detergente neutro; ${ }^{9}$ Nitrogênio insolúvel em detergente ácido; ${ }^{10}$ Carboidratos totais; ${ }^{11}$ Carboidrato não fibrosos; ${ }^{12}$ Digestibilidade in vitro da matéria seca; ${ }^{13} \%$ da MS; $;{ }^{14} \%$ do NT.

Os dados foram interpretados por análise de variância, estudo de regressão por meio de polinômios ortogonais, para o fator quantitativo, referente aos níveis de farelo de mandioca adicionados à ensilagem do capim-elefante e a aplicação de teste $\mathrm{F}$, para $\mathrm{o}$ fator qualitativo, referente ao emurchecimento (com e sem emurchecimento). No estudo de regressão por meio de polinômios ortogonais, na escolha dos modelos, foram considerados a significância, os coeficientes de determinação e o comportamento observado para a variável em questão. Adotou-se o nível de significância de 5\% de probabilidade e utilizou-se o 
Rev. Bras. Saúde Prod. Anim., Salvador, v.13, n.4, p.1020-1031 out./dez., 2012 http://www.rbspa.ufba.br ISSN 15199940

Statistical Analysis System (SAS INSTITUTE, 1999).

\section{RESULTADOS E DISCUSSÃO}

Os teores de carboidratos totais foram influenciados $(\mathrm{P}<0,05)$ apenas pelos níveis de farelo de mandioca. A análise de regressão revelou que o aumento dos níveis de farelo de mandioca na ensilagem provocou uma elevação dos teores de carboidratos totais, a estimar acréscimo de 0,16 unidades percentuais para cada unidade de farelo de mandioca adicionada (Tabela 2). Isso provavelmente ocorreu devido ao elevado teor de carboidrato deste subproduto.

Além disso, os valores de carboidratos são afetados pelos valores de PB e EE, haja vista a utilização dessas variáveis para determinação dos mesmos. Portanto, como o farelo de mandioca apresenta baixos valores desses nutrientes (Tabela 1), provavelmente, provocou resposta positiva aos acréscimos do aditivo utilizado.

Tabela 2. Teores médios de carboidratos totais, carboidratos não fibrosos $(A+B 1)$, componentes da parede celular disponíveis, que correspondem à fração potencialmente degradável (B2) e fração indigestível da parede celular (C) do capim-elefante ensilado, com e sem emurchecimento e farelo de mandioca (FM)

\begin{tabular}{|c|c|c|c|c|c|c|}
\hline \multirow{2}{*}{ Emurchecimento } & \multicolumn{4}{|c|}{ Farelo de Mandioca (\% MN) } & \multirow{2}{*}{$\mathrm{CV}(\%)$} & \multirow{2}{*}{$\begin{array}{l}\text { Equação de } \\
\text { regressão }\end{array}$} \\
\hline & 0,0 & 7,5 & 15,0 & 22,5 & & \\
\hline \multicolumn{7}{|c|}{ CHOT (\% MS) } \\
\hline Sem & $79,6^{\mathrm{a}}$ & $80,0^{\mathrm{a}}$ & $81,8^{a}$ & $83,2^{\mathrm{a}}$ & \multirow{2}{*}{1,0} & \multirow{2}{*}{1} \\
\hline Com & $79,5^{\mathrm{a}}$ & $80,8^{\mathrm{a}}$ & $82,7^{\mathrm{a}}$ & $83,0^{\mathrm{a}}$ & & \\
\hline \multicolumn{7}{|c|}{$\mathrm{A}+\mathrm{B} 1(\% \mathrm{CHOT})$} \\
\hline Sem & $11,0^{\mathrm{a}}$ & $22,8^{\mathrm{a}}$ & $35,6^{\mathrm{a}}$ & $43,6^{\mathrm{a}}$ & \multirow{2}{*}{5,5} & 2 \\
\hline Com & $11,0^{\mathrm{a}}$ & $23,3^{\mathrm{a}}$ & $31,0^{\mathrm{b}}$ & $38,3^{b}$ & & 3 \\
\hline \multicolumn{7}{|c|}{$\mathrm{B} 2(\% \mathrm{CHOT})$} \\
\hline Sem & $51,5^{\mathrm{a}}$ & $45,0^{\mathrm{a}}$ & $37,1^{b}$ & $32,6^{b}$ & \multirow{2}{*}{3,7} & 4 \\
\hline Com & $51,2^{\mathrm{a}}$ & $44,8^{\mathrm{a}}$ & $40,7^{\mathrm{a}}$ & $37,1^{\mathrm{a}}$ & & 5 \\
\hline \multicolumn{7}{|c|}{$\mathrm{C}(\% \mathrm{CHOT})$} \\
\hline Sem & $37,4^{\mathrm{a}}$ & $32,3^{\mathrm{a}}$ & $27,3^{\mathrm{a}}$ & $23,8^{\mathrm{a}}$ & \multirow{2}{*}{3,8} & \multirow{2}{*}{6} \\
\hline Com & $37,9^{\mathrm{a}}$ & $31,9^{\mathrm{a}}$ & $28,3^{\mathrm{a}}$ & $24,5^{\mathrm{a}}$ & & \\
\hline
\end{tabular}

Médias seguidas de uma mesma letra em uma mesma coluna não diferem entre si pelo teste $\mathrm{F}$ a $5 \%$ de probabilidade; $\hat{\mathrm{Y}}^{1}=79,4428+0,1678 \mathrm{FM}\left(\mathrm{r}^{2}=0,93\right) ; \quad \hat{\mathrm{Y}}^{2}=11,7363+1,4706 \mathrm{FM}\left(\mathrm{r}^{2}=0,99\right) ;$ $\hat{\mathrm{Y}}^{3}=12,3030+1,2042 \mathrm{FM}\left(\mathrm{r}^{2}=0,98\right) ; \hat{\mathrm{Y}}^{4}=51,1790-0,8576 \mathrm{FM}\left(\mathrm{r}^{2}=0,99\right) ; \hat{\mathrm{Y}}^{5}=50,4542-0,6198$ FM $\left(r^{2}=0,98\right) ; \hat{Y}^{6}=37,1660-0,5989$ FM $\left(r^{2}=0,99\right)$

Pires et al. (2009), ao determinarem as frações que compõem os carboidratos e as proteínas da silagem de capim-elefante com $15 \%$ de farelo de mandioca, observaram teor de carboidrato total de
$88,6 \%$. Esse resultado foi superior ao aqui descrito (Tabela 2).

Para os valores de $\mathrm{A}+\mathrm{B} 1$ (em $\%$ dos $\mathrm{CHO})$, verificou-se interação $(\mathrm{P}<0,05)$ entre emurchecimento e níveis de farelo 
de mandioca. Ao se avaliar o efeito de emurchecimento dentro dos níveis de farelo de mandioca, observou-se ainda diferença $(\mathrm{P}<0,05)$ apenas para as silagens dos níveis 15 e $22,5 \%$ de farelo de mandioca em que as silagens sem emurchecimento apresentaram valores superiores às não emurchecidas (Tabela 2).

Por meio da análise de regressão, observou-se comportamento linear crescente para as silagens, sem e com emurchecimento, cujos acréscimos de 1,4 e 1,2 unidade percentual foram estimados para cada unidade de farelo de mandioca adicionada. Esses incrementos da fração $\mathrm{A}+\mathrm{B} 1$ podem ser justificados pelo fato de o farelo de mandioca ser muito rico em amido. Possivelmente, o amido presente foi o responsável pelas elevações observadas, uma vez que a fração $\mathrm{A}+\mathrm{B} 1$ das silagens sem o farelo representa apenas $11 \%$ dos $\mathrm{CHO}$ (Tabela 2). Ao se considerar que a fermentação ruminal e a digestão pósruminal dependem da concentração total de carboidratos e proteínas na dieta e de suas taxas de degradação (MELLO \& NÖRNBERG, 2004), a elevação da fração $\mathrm{A}+\mathrm{B} 1$ das silagens estudadas representa um favorecimento dietético no que concerne ao atendimento dos requisitos nutricionais dos animais.

As silagens de capim-elefante não emurchecido e emurchecido sem farelo de mandioca apresentaram $11 \%$ de fração $\mathrm{A}+\mathrm{B} 1$ (\% $\mathrm{CHO})$, inferior aos $14,7 \%$ relatados por Cabral et al. (2004). Embora a composição bromatológica das silagens fosse próxima, foi verificada diferença na fração supracitada.

Para a fração B2 (\% CHO), verificou-se interação $(\mathrm{P}<0,05)$ entre emurchecimento e níveis de farelo de mandioca. Ao se analisar o efeito de emurchecimento dentro dos níveis de farelo de mandioca, verificou-se diferença $(\mathrm{P}<0,05)$ apenas para os níveis de 15 e $22,5 \%$ de farelo de mandioca, cujos maiores valores foram atribuídos às silagens emurchecidas. Quando analisados os valores da fração B2, em função dos níveis de farelo de mandioca, constatou-se, por meio da análise de regressão, comportamento linear decrescente, de modo a estimar reduções de 0,8 e 0,6 unidade percentual para cada unidade de farelo de mandioca, adicionado às silagens sem $\mathrm{e}$ com emurchecimento, respectivamente. Provavelmente, o baixo teor de FDN do resíduo utilizado (Tabela 1) tenha reduzido, por efeito de diluição, os valores dessa fração.

De forma semelhante, Carvalho et al. (2007a), ao determinarem as frações que compõem os carboidratos da silagem de capim-elefante emurchecido ou acrescida de farelo de cacau, verificaram redução de 0,7 unidade percentual na fração B2, valor próximo aos encontrados neste experimento.

Alimentos volumosos geralmente possuem altos teores de FDN e, portanto, apresentam maiores valores da fração B2 de carboidratos. Tal componente fornece energia lentamente no rúmen e pode afetar a eficiência de síntese microbiana e o desempenho animal. Nesses casos, a forragem deve ser suplementada com fontes energéticas de rápida disponibilidade no rúmen, quando não apresentar limitações proteicas em quantidade e qualidade. Nesse sentido, o farelo de mandioca mostrou-se eficiente na redução dessa fração, o que o configura como alternativa de fonte de carboidratos potencialmente digeríveis.

Com relação à fração $\mathrm{C}$ dos carboidratos, representada pela $\mathrm{FDNi}$, verificou-se efeito $(\mathrm{P}<0,05)$ apenas de farelo de mandioca (Tabelas 2). A adição de farelo na produção das silagens reduziu linearmente a fração $\mathrm{C}$ dos carboidratos, de modo a tornar possível a estimação de decréscimos de 0,6 unidade percentual para cada unidade de farelo de mandioca 
adicionado. Possivelmente, isso decorre dos baixos valores de lignina das silagens produzidas com a inclusão do farelo de mandioca, em comparação às silagens sem farelo de mandioca. Tal farelo apresenta baixos valores de lignina (Tabela 1), o que, possivelmente, reduziu os níveis desse composto nas silagens, de modo a interferir positivamente nos valores da fração $\mathrm{C}$, a qual, nutricionalmente, representa a fibra indisponível para os ruminantes (SNIFFEN et al., 1992).

No tocante às frações nitrogenadas das silagens estudadas para o teor de PB, verificou-se interação $(\mathrm{P}<0,05)$ entre emurchecimento e níveis de farelo de mandioca. Ao analisar o efeito de emurchecimento dentro dos níveis de farelo de mandioca, para os teores de $\mathrm{PB}$, observou-se diferença $(\mathrm{P}<0,05)$ apenas para a silagem sem a inclusão de farelo de mandioca (Tabela 3). Por outro lado, ao se avaliarem os teores de PB em função dos níveis de farelo, para as silagens sem emurchecimento, observou-se que aqueles não foram influenciados por tais níveis, cujo valor médio apresentado foi de $7,41 \%$.

Tabela 3. Teores médios de proteína bruta, fração constituída de nitrogênio não proteico (A), fração de rápida e de intermediária degradação $(\mathrm{B} 1+\mathrm{B} 2)$, fração de lenta degradação (B3) e fração não digestível (C) do capim-elefante ensilado com e sem emurchecimento e farelo de mandioca (FM)

\begin{tabular}{|c|c|c|c|c|c|c|}
\hline \multirow{2}{*}{ Emurchecimento } & \multicolumn{4}{|c|}{ Farelo de Mandioca (\% MN) } & \multirow{2}{*}{$\mathrm{CV}(\%)$} & \multirow{2}{*}{$\begin{array}{c}\text { Equação de } \\
\text { regressão }\end{array}$} \\
\hline & 0,0 & 7,5 & 15,0 & 22,5 & & \\
\hline \multicolumn{7}{|c|}{$\mathrm{PB}(\% \mathrm{MS})$} \\
\hline Sem & $7,0^{b}$ & $7,9^{\mathrm{a}}$ & $7,5^{\mathrm{a}}$ & $7,3^{\mathrm{a}}$ & \multirow{2}{*}{6,7} & 1 \\
\hline Com & $7,9^{\mathrm{a}}$ & $7,4^{\mathrm{a}}$ & $7,1^{\mathrm{a}}$ & $7,0^{\mathrm{a}}$ & & 2 \\
\hline \multicolumn{7}{|c|}{$\mathrm{A}(\% \mathrm{NT})$} \\
\hline Sem & $59,4^{\mathrm{a}}$ & $59,1^{\mathrm{a}}$ & $60,5^{\mathrm{a}}$ & $61,5^{\mathrm{a}}$ & \multirow{2}{*}{13,7} & \multirow{2}{*}{3} \\
\hline Com & $60,4^{\mathrm{a}}$ & $59,6^{\mathrm{a}}$ & $48,8^{\mathrm{a}}$ & $60,3^{\mathrm{a}}$ & & \\
\hline \multicolumn{7}{|c|}{$\mathrm{B} 1+\mathrm{B} 2(\% \mathrm{NT})$} \\
\hline Sem & $28,5^{\mathrm{a}}$ & $30,5^{\mathrm{a}}$ & $29,2^{\mathrm{a}}$ & $27,6^{\mathrm{a}}$ & \multirow{2}{*}{26,6} & \multirow{2}{*}{4} \\
\hline Com & $30,1^{\mathrm{a}}$ & $28,7^{\mathrm{a}}$ & $39,9^{\mathrm{a}}$ & $28,5^{\mathrm{a}}$ & & \\
\hline \multicolumn{7}{|c|}{$\mathrm{B} 3(\% \mathrm{NT})$} \\
\hline Sem & $3,0^{\mathrm{a}}$ & $3,0^{\mathrm{a}}$ & $3,3^{\mathrm{a}}$ & $3,8^{\mathrm{a}}$ & \multirow{2}{*}{30,1} & 5 \\
\hline Com & $0,54^{\mathrm{b}}$ & $3,4^{\mathrm{a}}$ & $2,4^{\mathrm{a}}$ & $1,2^{\mathrm{b}}$ & & 6 \\
\hline \multicolumn{7}{|c|}{$\mathrm{C}(\% \mathrm{NT})$} \\
\hline Sem & $9,1^{\mathrm{a}}$ & $7,4^{\mathrm{a}}$ & $6,9^{b}$ & $7,1^{b}$ & \multirow{2}{*}{11,0} & 7 \\
\hline Com & $9,0^{\mathrm{a}}$ & $8,3^{\mathrm{a}}$ & $9,0^{\mathrm{a}}$ & $10,0^{\mathrm{a}}$ & & 8 \\
\hline
\end{tabular}

Médias seguidas de uma mesma letra em uma mesma coluna não diferem entre si pelo teste $\mathrm{F}$ a $5 \%$ de probabilidade; $\hat{\mathrm{Y}}^{1}=7,41 ; \hat{\mathrm{Y}}^{2}=7,83322-0,0429201 \mathrm{FM}\left(\mathrm{r}^{2}=0,93\right) ; \hat{\mathrm{Y}}^{3}=58,7 ; \hat{\mathrm{Y}}^{4}=30,4 ; \hat{\mathrm{Y}}^{5}=3,26$; $\hat{\mathrm{Y}}^{6}=0,7475+0,416333 \mathrm{FM}-0,01800 \mathrm{FM}^{2}\left(\mathrm{r}^{2}=0,84\right) ; \hat{\mathrm{Y}}^{7}=8,5825-0,084 \mathrm{FM}\left(\mathrm{r}^{2}=0,70\right) ; \hat{\mathrm{Y}}^{8}=9,06$

A silagem emurchecida apresentou comportamento linear decrescente, a apresentar redução de $0,04 \%$ para cada unidade de farelo de mandioca adicionada. Tal comportamento já era esperado, pois o subproduto utilizado apresenta baixos valores de $\mathrm{PB}$, o que reduziu os teores de proteína das 
silagens aditivadas com farelo de mandioca.

Resposta diferente às observadas aqui foram encontradas por Pinho et al. (2008). Os autores, ao avaliarem a silagem de capim-elefante com diferentes níveis de farelo de mandioca, observaram redução da proteína bruta em 0,09 unidades percentuais para cada unidade de farelo de mandioca adicionada, cujos valores apresentados são de 7,$1 ; 6,9$; 6,$5 ; 6,0$ para os níveis de $0 ; 4 ; 8$ e $12 \%$ de farelo de mandioca.

Para as frações A e B1+B2 da proteína bruta, não se verificou efeito $(\mathrm{P}>0,05)$ para os tratamentos emurchecimento, farelo de mandioca, nem para a interação entre emurchecimento e farelo de mandioca. Nenhuma equação de regressão se ajustou aos dados, cujo valor médio registrado foi de 58,7 e $30,4 \%$, respectivamente, para as frações supracitadas (Tabela 3 ).

$\mathrm{O}$ teor de nitrogênio não proteico (NNP) ou fração A, obtido para as silagens de capim-elefante, não emurchecido e emurchecido, foi de 59,4 e 60,4\%. Esses números são superiores aos encontrados por Carvalho et al. (2008), de 47,6 e $50,7 \%$, respectivamente, para as silagens sem e com emurchecimento.

O fracionamento dos compostos nitrogenados das espécies estudadas revelou alta proporção de frações solúveis na $\mathrm{PB}$, possivelmente, em virtude da fermentação no silo, em que grande porção da proteína da planta, representada pela ribulose 1,5- bisfosfato carboxilase oxigenase (RUBISCO), por ser altamente susceptível à proteólise, pode ser convertida a NNP. Entre os fatores predisponentes à proteólise, o teor de umidade e, consequentemente, o pH elevado, são os principais (VAN SOEST, 1994). De forma semelhante, Andrade et al. (2010), verificaram que a fração A das silagens de capim-elefante não foi influenciada pelos níveis de farelo de mandioca, cujo valor médio apresentado foi de $33,1 \%$.

No tocante às frações B1 e B2, pode-se observar que estas foram determinadas como fração única $(\mathrm{B} 1+\mathrm{B} 2)$. Nem todo fracionamento proteico feito pelo Cornell Net Carbohydrate and Protein System (CNCPS) deveria ser adotado no Brasil. Apenas deveriam ser obrigatórias, além da análise de PB, pelo menos a determinação da fração dos compostos nitrogenados não proteicos e das frações NIDA e NIDN, isto é, as frações A e $\mathrm{C}$ e, por diferença (NIDN - NIDA), a fração B3, sem haver, portanto, necessidade de separar a proteína solúvel (B1) da insolúvel (B2), de acordo com Valadares Filho (2000).

Os valores de $\mathrm{B} 1+\mathrm{B} 2$, obtidos para as silagens, sem e com emurchecimento, sem a adição de farelo de mandioca, foram de 28,5 e $30,1 \%$, respectivamente. Tais valores são superiores aos $22,4 \%$ encontrados por Cabral et al. (2004) e próximos aos 29,6 e 33,7\% encontrados por Carvalho et al. (2008) para silagem de capim-elefante. Cabral et al. (2004), provavelmente, verificaram os menores valores da fração $\mathrm{B} 1+\mathrm{B} 2$, porque a silagem produzida tenha utilizado capim-elefante com 120 dias de crescimento, o que pode ter contribuído para a redução dos valores da fração supracitada. Cabe lembrar que com o avançar do estágio de desenvolvimento tende a concentrar as frações de menor taxa de digestão.

De forma semelhante, Pires et al. (2009), ao avaliarem as frações que compõem os carboidratos e as proteínas da silagem de capim-elefante com 15\% casca de café, farelo de cacau ou farelo de mandioca, observaram valores para a fração B1+B2 (\% PB) na silagem de capim-elefante com $15 \%$ de farelo de mandioca, resultado semelhante ao aqui registrado. 
Verificou-se interação significativa $(\mathrm{P}<0,05)$ entre emurchecimento e níveis de farelo de mandioca, para as frações proteicas B3 e C. Ao se avaliar o efeito de emurchecimento dentro dos níveis de farelo de mandioca, para a fração B3, observa-se diferença $(\mathrm{P}<0,05)$ apenas para os níveis 0 e $22,5 \%$ de farelo de mandioca, cujos maiores valores são atribuídos à silagem sem emurchecimento. Por outro lado, ao se analisar a fração B3, em função dos níveis de farelo de mandioca, para as silagens sem emurchecimento, observase que esta não foi influenciada pelos níveis de farelo de mandioca, e o valor médio apresentado foi de 3,26\% (Tabela 3 ). No que concerne à silagem emurchecida, constata-se, por meio da análise de regressão, comportamento quadrático, cujo valor máximo estimado foi de $3,1 \%$ para o nível de $11,5 \%$ de farelo de mandioca.

A fração B3 das silagens estudadas foi baixa, como observado na Tabela 3 . Como esta fração é representada pelas proteínas de ligação da parede celular, que apresentam lenta taxa de degradação (CABRAL et al., 2004), ela é lentamente degradada no rúmen e, portanto, apresenta elevado escape, o que faz com que seja potencial fonte de aminoácidos no intestino delgado (SNIFFEN et al., 1992). Contudo, podese inferir que a silagem de capimelefante não é boa fonte da fração B3. Possivelmente, como a inclusão do farelo de mandioca reduz a fração fibrosa e a PB da silagem, a adição do aditivo supracitado, diminui a proteína não degradada no rúmen, pois baixos valores de B3 foram observados nas silagens (Tabela 3 ).

Resultados diferentes aos observados neste estudo foram verificados por Andrade et al. (2010). Tais estudiosos, ao pesquisarem a influência da adição de farelo de mandioca, na ensilagem do capim-elefante sobre a composição das frações que compõem as proteínas e os carboidratos, relataram que o aumento dos níveis de farelo de mandioca teve efeito linear nos teores dessa fração, a promover acréscimo de 0,34 unidade percentual a cada $1 \%$ de farelo de mandioca adicionado ao capim-elefante no momento da ensilagem.

Com relação à fração $\mathrm{C}$, sabe-se que esta corresponde à proteína indisponível, insolúvel em detergente ácido e abreviada por NIDA. Essa fração contém proteínas associadas à lignina, taninos e compostos de Maillard altamente resistentes à degradação microbiana e enzimática e é considerada inaproveitável, tanto no rúmen como pós-ruminalmente (SNIFFEN et al., 1992).

Como já relatado, a fração $\mathrm{C}$ apresentou interação significativa $(\mathrm{P}<0,05)$ entre emurchecimento e níveis de farelo de mandioca. Ao se analisar o efeito de emurchecimento dentro dos níveis de farelo de mandioca, para a fração $\mathrm{C}$, contata-se diferença apenas para os níveis 15,0 e $22,5 \%$ de inclusão de farelo de mandioca e os maiores valores foram atribuídos para as silagens emurchecidas. Ao se avaliar a fração $\mathrm{C}$ em função dos níveis de farelo de mandioca, para as silagens sem emurchecimento, observa-se que a análise de regressão revelou comportamento linear decrescente, a estimar redução de $0,08 \%$ para cada unidade de farelo de mandioca adicionada. Com relação à silagem emurchecida, verifica-se que esta não foi influenciada pelos níveis de farelo de mandioca, de modo a apresentar valor médio de 9,0\%.

Os valores aqui observados são inferiores aos encontrados por Carvalho et al. (2008). Esses pesquisadores, ao determinarem as frações proteicas da silagem de capim-elefante emurchecida ou não, verificaram valores de 10,6 e $15,3 \%$ da fração $C$ para as silagens 
emurchecidas e não emurchecidas, respectivamente. Por outro lado, Cabral et al. (2004) observaram valor de $8,8 \%$ da fração C para a silagem de capimelefante, ou seja, número próximo ao encontrado no presente estudo (Tabela 3). Segundo Van Soest (1994), o aumento da fração $\mathrm{C}$ de silagens pode ocorrer devido à formação de produtos da reação de Maillard, em razão do aumento da temperatura em silagens com elevado teor de umidade. Ao se considerar que as silagens apresentam ambiente heterogêneo, as diferenças observadas com relação aos trabalhos supracitados sejam em decorrência da condição em que cada silagem foi produzida, bem como das reações ocorridas nas massa ensilada.

Os parâmetros fermentativos apresentaram interação significativa $(\mathrm{P}<0,05)$ entre emurchecimento e níveis de farelo de mandioca para $\mathrm{pH}$ e $\mathrm{N}-\mathrm{NH}_{3}$ das silagens (Tabela 4).

Tabela 4. Médias de $\mathrm{pH}$ e teores médios de nitrogênio amoniacal $\left(\mathrm{N}-\mathrm{NH}_{3}\right)$ do capimelefante ensilado com e sem emurchecimento e farelo de mandioca (FM)

\begin{tabular}{|c|c|c|c|c|c|c|}
\hline \multirow{2}{*}{ Emurchecimento } & \multicolumn{4}{|c|}{ Farelo de Mandioca (\% MN) } & \multirow{2}{*}{$\mathrm{CV}(\%)$} & \multirow{2}{*}{$\begin{array}{l}\text { Equação de } \\
\text { regressão }\end{array}$} \\
\hline & 0,0 & 7,5 & 15,0 & 22,5 & & \\
\hline \multicolumn{7}{|c|}{$\mathrm{pH}$} \\
\hline Sem & $4,1^{\mathrm{a}}$ & $3,8^{\mathrm{a}}$ & $3,8^{\mathrm{a}}$ & $3,8^{\mathrm{a}}$ & \multirow{2}{*}{0,92} & 1 \\
\hline Com & $3,7^{\mathrm{b}}$ & $3,7^{\mathrm{b}}$ & $3,6^{\mathrm{b}}$ & $3,7^{\mathrm{b}}$ & & 2 \\
\hline \multicolumn{6}{|c|}{$\mathrm{N}-\mathrm{NH}_{3}(\% \mathrm{NT})$} & \\
\hline Sem & $4,9^{\mathrm{a}}$ & $2,7^{\mathrm{a}}$ & $2,5^{\mathrm{a}}$ & $2,6^{\mathrm{a}}$ & \multirow{2}{*}{12,0} & 3 \\
\hline Com & $3,5^{\mathrm{b}}$ & $3,0^{\mathrm{a}}$ & $2,5^{\mathrm{a}}$ & $2,5^{\mathrm{a}}$ & & 4 \\
\hline
\end{tabular}

Médias seguidas de uma mesma letra em uma mesma coluna não diferem entre si pelo teste $\mathrm{F}$ a $5 \%$ de probabilidade; $\hat{\mathrm{Y}} 1=4,09163-0,0399500 \mathrm{FM}+0,00125556 \mathrm{FM}^{2}\left(\mathrm{r}^{2}=0,92\right) ; \hat{\mathrm{Y}}^{2}=3,70537-$ $0,00845000 \mathrm{FM}+0,000344444 \mathrm{FM}^{2}\left(\mathrm{r}^{2}=0,99\right) ; \quad \hat{\mathrm{Y}}^{3}=4,82380-0,328975 \mathrm{FM}+0,0104297 \mathrm{FM}^{2}$ $\left(r^{2}=0,96\right) ; \hat{Y}^{4}=3,36298-0,0452628 \mathrm{FM}\left(\mathrm{r}^{2}=0,88\right)$

Ao se analisar o efeito de emurchecimento dentro do nível de farelo de mandioca, observou-se menor $(\mathrm{P}<0,05)$ valor de $\mathrm{pH}$ para as silagens com emurchecimento. No que respeita ao $\mathrm{pH}$, em função dos níveis de farelo de mandioca, observou-se comportamento quadrático para ambas as silagens. Para a silagem sem emurchecimento, estimou-se valor mínimo de $\mathrm{pH}$ igual a 3,7 para o nível de $15,9 \%$ de farelo de mandioca. Já para a silagem com emurchecimento, o valor mínimo estimado foi 3,6 para o nível de $12,2 \%$ de farelo de mandioca (Tabela 4). Os valores de $\mathrm{pH}$ observados indicam que o processo fermentativo ocorreu de forma satisfatória, uma vez que esses valores encontram-se entre 3,8 a 4,2, índice referencial e indicativo de silagem de qualidade.

No que concerne ao nitrogênio amoniacal $\left(\mathrm{N}-\mathrm{NH}_{3}\right)$, ao se avaliar o efeito de emurchecimento dentro do nível de farelo de mandioca, observouse diferença $(\mathrm{P}<0,05)$ no valor de $\mathrm{N}$ $\mathrm{NH}_{3}$ apenas para as silagens sem e com emurchecimento sem a adição de farelo de mandioca (Tabela 4). Ao se analisar o N-NH $\mathrm{NH}_{3}$ em função dos níveis de farelo de mandioca, verificou-se, por meio da análise de regressão, comportamento quadrático e linear decrescente para as silagens sem e com emurchecimento, respectivamente, cujo valor mínimo foi 
de $2,2 \%$ para o nível de $15,7 \%$ de farelo de mandioca para a silagem sem emurchecimento.

Já para a silagem com emurchecimento, constatou-se decréscimo de 0,04 unidades percentuais para cada unidade de farelo de mandioca adicionada. Todos os valores para o $\mathrm{N}-\mathrm{NH}_{3}$ estão abaixo do valor máximo de $10 \%$ de $\mathrm{N}$ $\mathrm{NH}_{3}$, tal resultado indica que as silagens produzidas são de qualidade uma vez que não ocorreu degradação excessiva das proteínas presentes no capimelefante, de modo a produzir um alimento de melhor valor nutritivo.

A utilização do farelo de mandioca reduz a fração B2 e a porção de carboidratos indisponíveis. As principais frações proteicas das silagens estudadas são as frações A e B1+B2. O emurchecimento e a adição de farelo de mandioca melhora $\mathrm{o}$ valor nutritivo e as características fermentativas das silagens estudadas.

\section{REFERÊNCIAS}

ANDRADE, I.V.O.; PIRES, A.J.V.P.; CARVALHO, G.G.P.; VELOSO, C.M.; BONOMO, P. Fracionamento de proteína e carboidratos em silagens de capim-elefante contendo subprodutos agrícolas. Revista Brasileira de

Zootecnia, v.39, n.11, p.2342-2348, 2010.

\section{CABRAL, L.S.; VALADARES} FILHO, S.C.; DETMANN, E.; ZERVOUDAKIS, J.T.; VELOSO, R.G.; NUNES, P.M.M. Taxas de digestão das frações protéicas e de carboidratos para as silagens de milho e de capim-elefante, o feno de capimtifton-85 e o farelo de soja. Revista Brasileira de Zootecnia, v.33, n.6, p.1573-1580, 2004.
CARVALHO, G.G.P.; GARCIA, R.; PIRES, A.J.V. PEREIRA, O.G.; FERNANDES, F.É.P.; CECON, P.R.; AZEVÊDO, J.A.G. Fracionamento de proteínas de silagem de capim-elefante emurchecido ou com farelo de cacau. Ciência Animal Brasileira, v.9, n.3, p.648-656, 2008.

CARVALHO, G.G.P.; GARCIA, R.; PIRES, A.J.V.; PEREIRA, O.G.; FERNANDES, F.É.P.; OBEID, J.A.; CARVALHO, B.M.A. Fracionamento de carboidratos de silagem de capimelefante emurchecido ou com farelo de cacau. Revista Brasileira de Zootecnia, v.36, n.4, p.1000-1005, 2007a. Supl.

CARVALHO, G.G.P.; GARCIA, R.; PIRES, A.J.V., PEREIRA,O.G., AZEVÊDO, J.A.G. CARVALHO, B.M.A.DE., CAVALI, J. Valor nutritivo de silagens de capim-elefante emurchecido ou com adição de farelo de cacau. Revista Brasileira de

Zootecnia, v.36, n.5, p.1495-1501, 2007b.

CARVALHO, G.G.P.; GARCIA, R.; PIRES, A.J.V., AZEVÊDO, J.A.G.; FERNANDES, F.E.P.; PEREIRA, O.G. Valor nutritivo e características fermentativas de silagem de capimelefante com adição de casca de café.

Revista Brasileira de Zootecnia, v.36, n.6, p.1875-1881, 2007c.

CUNNIFF, P. Official methods of analysis of AOAC International. 16ed. Arlington: AOAC International, 1995. v.1, p.7-8.

EMPRESA BRASILEIRA DE PESQUISA AGROPECUÁRIA. EMBRAPA. Sistema brasileiro de classificação de solos. 2.ed. Rio de Janeiro: EMBRAPA/Centro Nacional de Pesquisa de Solos, 2006. 306p. 
GESUALDI JUNIOR, A.; QUEIROZ, A.C.; RESENDE, F.D. LANA, R.P.; GESUALDI, A.C.L.S.; ALLEONI, G.F.; DETMANN, E.; RAZOOK, A.G.; FIGUEIREDO, L.A. Validação dos sistemas VIÇOSA, CNCPS e NRC para formulação de dietas para bovinos Nelore e Caracu, não-castrados, selecionados em condições brasileiras.

Revista Brasileira de Zootecnia, v.34, n.3, p.997-1005, 2005.

HALL, M.B. Challenges with nonfiber carbohydrate methods. Journal of Animal Science, v.81, n.12, p.32263232, 2003.

MELLO, R.; NÖRNBERG, J.L. Fracionamento dos carboidratos e proteínas de silagens de milho, sorgo e girassol. Ciência Rural, v.34, n.5, p.1537-1542, 2004.

PEREIRA, J.R.A; ROSSI JUNIOR, P.P. Manual de avaliação nutricional de alimentos. Piracicaba: Fundação de Estudos Agrários Luiz de Queiroz, 1994. 34p.

PINHO, B.D; PIRES, A.J.V; RIBEIRO, L.S.O; CARVALHO, G.G.P. Ensilagem de capim-elefante com farelo de mandioca Revista Brasileira de Saúde Produção Animal [Online], v.9, n.4, p.641-651, 2008.

PIRES, A.J.V.; CARVALHO, G.G.P.; GARCIA, R.; CARVALHO JUNIOR, J.N.; RIBEIRO, L.S.O.; CHAGAS, D.M. T.Fracionamento de carboidratos e proteínas de silagens de capimelefante com casca de café, farelo de cacau ou farelo de mandioca. Revista Brasileira de Zootecnia, v.38, n.3, p.422-427, 2009.
REZENDE, A.V.; EVANGELISTA, A.R.; BARCELOS, A.F.; SIQUEIRA, G.R.; SANTOS, R.V.; MAZO, M.S. Efeito da mistura da planta de girassol (Helianthus annuus L.) durante a ensilagem do capim-elefante (Pennisetum purpureum Schum.) no valor nutritivo da silagem. Revista Brasileira de Zootecnia, v.31, n.5, p.1938-1943, 2002.

SAS INSTITUTE. Statistical analysis system: user's guide. Version 8.0. Cary: 1999. 295p.

SILVA, D.J.; QUEIROZ, A.C. Análise de alimentos: métodos químicos e biológicos. Viçosa: Universidade Federal de Viçosa, 2002. 235p.

SNIFFEN, C.J.; O'CONNOR, D.J.; VAN SOEST, P.J; FOX, D.G.; RUSSELL, J.B. A net carbohydrate and protein system for evaluating cattle diets: carbohydrate and protein availability. Journal of Animal Science, v.70, n.12, p.3562-3577, 1992.

VALADARES FILHO, S.C. Nutrição, avaliação de alimentos e tabelas de composição de alimentos para bovinos. In: REUNIÃO ANUAL DA SOCIEDADE BRASILEIRA DE ZOOTECNIA, 37., 2000, Viçosa, MG. Anais... Viçosa, MG: Sociedade Brasileira de Zootecnia, 2000. p.267337.

VAN SOEST, P.J. Nutritional ecology of the ruminant. 2.ed. Ithaca: Cornell University Press, 1994. 476p.

Data de recebimento: 29/03/2012

Data de aprovação: 27/11/2012 